\title{
A Single-Molecule Study on the Structural Damage of Ultraviolet Radiated DNA
}

\author{
Kathryn Schallhorn ${ }^{1,2}$, Mickey Kim ${ }^{1}$ and Pu Chun Ke ${ }^{1, *}$ \\ 1 Laboratory of Single-Molecule Biophysics and Polymer Physics, Clemson University, Clemson, \\ SC 29634-0978, USA \\ 2 Carl Zeiss MicroImaging, Inc. One Zeiss Drive, Thornwood, NY 10594, USA \\ * Author to whom correspondence should be addressed. Fax: 864-656-0558; \\ E-mail: pcke11@clemson.edu
}

Received: 21 December 2007; in revised form: 22 April 2008 / Accepted: 23 April 2008 /

Published: 24 April 2008

\begin{abstract}
The structural damage of double-stranded DNA under UV radiation was examined using single-molecule fluorescence microscopy. Compared to undamaged DNA, the diffusion coefficient of $\lambda$-DNA was significantly increased with $12 \mathrm{~min}$ or $20 \mathrm{~min}$ of radiation but remained unchanged for $40 \mathrm{~min}$ of exposure possibly due to strand crosslinking. The structural damage of DNA was further examined using transmission electron microscopy which revealed kinks and sharp bends along the DNA backbone.
\end{abstract}

Keywords: DNA damage; UV radiation; flexibility; diffusion.

\section{Introduction}

DNA photon absorption, on a time scale of $10^{-12} \mathrm{sec}$, can excite a pyrimidine base. In this excited state, energy can be released through various pathways, such as fluorescence, or reactions with other molecules forming unstable intermediates or stable photoproducts [1]. UV wavelength is known to play a significant role in the rate and type of damage. For example, UVB (290-320 nm) is a few orders of magnitude more potent than UVA (320-400 nm) in inducing carcinogens due to the increase in photon energy [2]. Although most of UVB is absorbed by the atmosphere, due to the degradation of stratospheric ozone, however, there has been a rise in UVB radiation at the earth's surface, and air 
pollutants threaten to enlarge ozone holes, exposing the environment to highly energetic UVC (100-290 nm) [1]. Specifically, at a dose of $420 \mathrm{~J} / \mathrm{m}^{2}$ of UVC radiation which corresponds to $20 \mathrm{hrs}$ of natural sunlight exposure at noon on a summer day in Los Angeles [3], one cyclobutane dipyrimidine dimer (CPD) is formed every 250-350 bp [4].

There are two main types of photoproducts induced by UVC radiation. The most common are CPDs, which involve two covalent bonds between adjacent pyrimidines [5]. For example, thyminethymine cyclobutane dimers (T-T dimer) occur with greater frequency compared to cytosine-thymine, thymine-cytosine, and cytosine-cytosine dimers [1]. Pyrimidine 6-4 pyrimidine photoproducts (6-4 PPs) involve a single covalent bond between positions 6 and 4 of adjacent pyrimidines. In vivo, if a photoproduct is not completely repaired, helix distorting photoproducts, such as CPDs, 6-4 PPs, and crosslinks, pose a mutagenic threat and such mutations could cause heritable changes in gene expression resulting in UV-induced skin cancers [5, 6]. Although UV induced DNA damage has been extensively studied, the structural damage of DNA has rarely been examined at the single-molecule level.

It is depicted by the reptation theory and the tube model that a linear polymer such as a doublestranded DNA (dsDNA), once entangled with other polymers, diffuses like a crawling snake in an imaginary tube confined by its neighboring polymer molecules [7-9]. Inhomogeneities of DNA, such as unwinding and bending induced by the formation of photoproducts, are expected to affect the diffusion coefficient of the molecule. In this paper we investigate the structural damage of UV-radiated DNA via a single-molecule diffusion study and complement this approach with a direct visualization of damaged DNA using transmission electron microscopy (TEM).

\section{Results and Discussion}

\subsection{Single-Molecule DNA Diffusion in the Presence of UV Damage}

For every CPD formed, a dsDNA molecule is unwound by $9.3^{\circ}$ and bent towards the major groove by $30^{\circ}[10]$, affecting the overall homogeneity of the DNA. Such structural damage can be reflected by monitoring the diffusion of DNA in semi-dilute or entangled state. Table 1 tabulates the average diffusion coefficients for undamaged (healthy) $\lambda$-DNA at $0.008 \pm 0.001 \mu \mathrm{m}^{2} / \mathrm{s}$, and $\lambda$-DNA under UVC radiation of $12 \mathrm{~min}$ and $20 \mathrm{~min}$ at $0.017 \pm 0.002 \mu \mathrm{m}^{2} / \mathrm{s}$ and $0.019 \pm 0.003 \mu \mathrm{m}^{2} / \mathrm{s}$, respectively. These measurements are qualitatively in agreement with our previous observation [11] that a base-pair mismatched DNA possessed a larger degree of flexibility than matched DNA due to the "bubble" formation in the former. After $40 \mathrm{~min}$ of UVC exposure, the diffusion coefficient drops back to $0.008 \pm 0.001 \mu \mathrm{m}^{2} / \mathrm{s}$; suggesting a structural impediment on the flexibility of the $\lambda$-DNA. A consideration for this behavior would be an increased likelihood of inter-strand (and intra-strand) crosslinking for longer exposure times. The frequency of 1 crosslink per kilo-base-pair with $5000 \mathrm{~J} / \mathrm{m}^{2}$ UVC radiation [12] is equivalent to our $40 \mathrm{~min}$ exposure at $7344 \mathrm{~J} / \mathrm{m}^{2}$. Even one crosslink, a covalent bond between pyrimidines of one or two overlapping strands, would create a complex limiting reptation. 
Table 1. Average diffusion coefficients of DNA in semi-dilute solutions

\begin{tabular}{|c|c|c|c|}
\hline UVC exposure & $\begin{array}{c}\text { Entanglement } \\
\text { concentration }\end{array}$ & $\mathrm{D}_{\text {ave }}\left(\mu \mathrm{m}^{2} / \mathrm{s}\right)$ & $\pm \mathrm{D}_{\operatorname{dev}}\left(\mu \mathrm{m}^{2} / \mathrm{s}\right)$ \\
\hline 0 & $0.35 \mu \mathrm{g} / \mu \mathrm{L}$ & 0.008 & 0.001 \\
\hline $12 \mathrm{~min}$ & $0.35 \mu \mathrm{g} / \mu \mathrm{L}$ & 0.017 & 0.002 \\
\hline $20 \mathrm{~min}$ & $0.35 \mu \mathrm{g} / \mu \mathrm{L}$ & 0.019 & 0.003 \\
\hline $40 \mathrm{~min}$ & $0.35 \mu \mathrm{g} / \mu \mathrm{L}$ & 0.008 & 0.001 \\
\hline Control 1 & $0 \mu \mathrm{g} / \mu \mathrm{L}$ & 0.404 & 0.054 \\
\hline Control 2 & DNA immobilized & 0.00095 & 0.00033 \\
\hline
\end{tabular}

Although extremely unlikely, the total possible of CPDs formed at our experimental doses can be as high as 20,209 dimers per strand. The total number of neighboring thymines ( $\mathrm{T}$ ), which facilitate T-T dimers, is 5,237. The total number of neighboring cytosines $(\mathrm{C})$ and thymines $(\mathrm{T})$ and neighboring $\mathrm{T}$ and $\mathrm{C}$, which promote $\mathrm{C}-\mathrm{T}$ and $\mathrm{T}-\mathrm{C}$ dimers, is 10,230. And the total number of neighboring cytosines, which promote $\mathrm{C}-\mathrm{C}$ dimmers, is 4,742 . The probability of CPD formation at every possible location is rare. In fact, bulk studies indicate the rate of induction for T-T, C-T, T-C, C-C dimers have a ratio of 68:13:16:3, for $1000 \mathrm{~J} / \mathrm{m}^{2}$ with UVC [1], corresponding to $3560 \mathrm{~T}-\mathrm{T}, 664 \mathrm{C}-\mathrm{T}, 818 \mathrm{~T}-\mathrm{C}$ and $142 \mathrm{C}-\mathrm{C}$ dimers (a total of 5184 per strand) in one lambda DNA molecule. However, this ratio will likely change with the amount of exposure due to the non-linear increase in CPD formation [13].

\subsection{Gel Electrophoresis in the Presence of UV Damage}

Figure 1. Gel electrophoresis of $\lambda$-DNA. Left to right: the wells contain healthy $\lambda$-DNA, skip a lane, and $6 \mathrm{~min}, 12 \mathrm{~min}, 20 \mathrm{~min}$, and $40 \mathrm{~min}$ UVC exposed $\lambda$-DNA. Note, in the far right lanes, fluorescence in the well is indicative of some damaged $\lambda$-DNA remained in the wells due to a structural impediment.

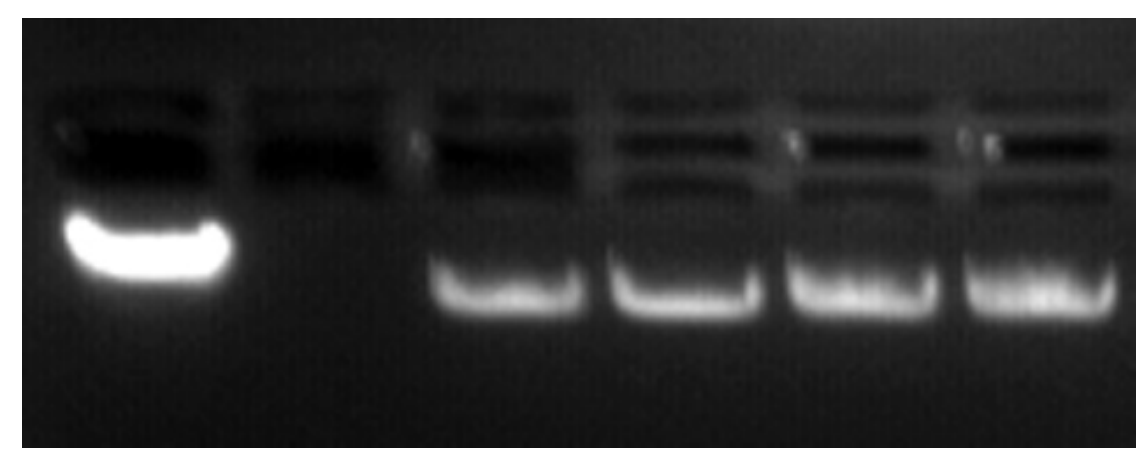

A comparison of the single-molecule data with gel electrophoresis maintains the trend of enhanced flexibility with exposure. Figure 1 demonstrates a noticeable increase in the distance traveled with damaged DNA (lanes 3-6) compared to healthy DNA (lane 1). The lane 1 containing the control (healthy $\lambda$-DNA) clearly displays a larger intensity, suggesting an expected homogeneity of this sample. The losses of band intensity (lanes 3-6) with greater degrees of damage suggest increased heterogeneity due to damage. Crosslinking may create large networks that cannot move through the agarose pores, and instead, are trapped in the top wells. The gel electrophoresis only looks at the 
sample in the band, but single-molecule data will include damaged DNA not resolved by the gel. Note the labeling of $\lambda$-DNA by ethidium bromide, on the other hand, could be hindered by the presence of photoproducts, due to the weakened base-pairing. This too can explain the reduction in band intensity.

\subsection{Transmission Electron Microscopy Study of DNA in the Presence of UV Damage}

We used TEM to further examine UVC-induced DNA damage. Note the sharp bends in Figure 2b) which rarely occur in Figure 2a), possibly indicating the presence of dimers due to UV radiation. Interestingly the loops and sharp bends in Figure 2 occurred on a scale much smaller than $50 \mathrm{~nm}$, the persistence length of dsDNA as predicted by the worm-like-chain model [9]. This is consistent with previous studies $[11,14,15]$ suggesting that short dsDNA, unlike a rigid rod, still possesses a certain degree of flexibility.

Figure 2. TEM images of a) healthy $\lambda$-DNA and b) $\lambda$-DNA after a 40 min UVC exposure. The sharp bends are highlighted with blue circles.

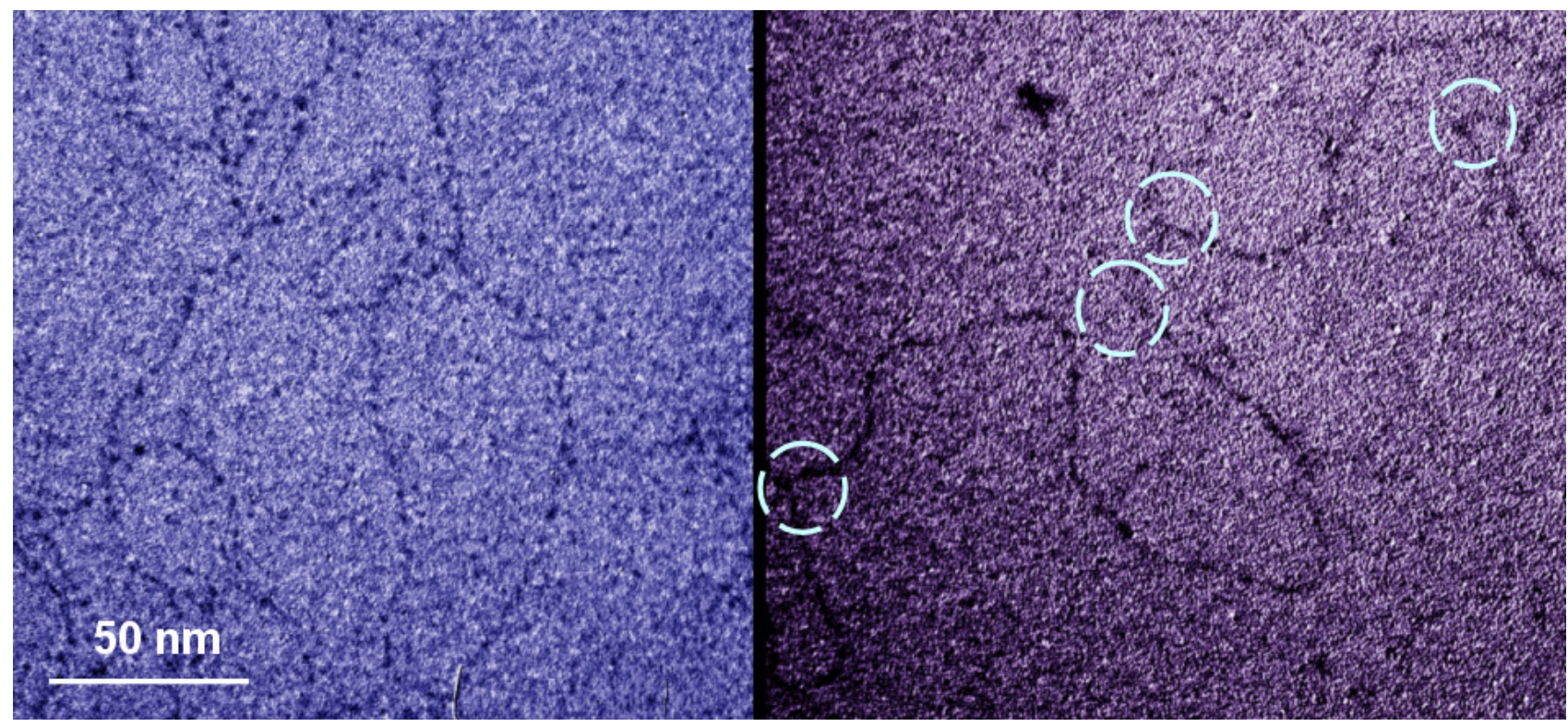

a)

b)

\section{Experimental Section}

\subsection{UVC Damage}

The formation of CPDs on $\lambda$-DNA (ordered from IDT, with a total of 48,502 base pairs) was induced by a germicidal lamp with a dose rate of $3.06 \mathrm{~J} / \mathrm{s} \cdot \mathrm{m}^{2}$. Radiation of $\lambda$-DNA in buffer T10 (10 $\mathrm{mM}$ Tris, $10 \mathrm{mM} \mathrm{NaCl}$, Milli-Q water, at $\mathrm{pH}$ of 7.34) occurred on ice for a series of exposure times ranging from $0 \mathrm{~min}, 12 \mathrm{~min}, 20 \mathrm{~min}$, and $40 \mathrm{~min}$.

\subsection{Single-Molecule Diffusion of DNA}

Post exposure, the $\lambda$-DNA was labeled with dye POPO-3 (Ex: $532 \mathrm{~nm}$; Em: $572 \mathrm{~nm}$ ) which only exhibited substantial fluorescence when bound to the DNA. Highly concentrated unlabeled $\lambda$-DNA, 
serving as the entanglement medium, was deconcatemerized by incubating at $74^{\circ} \mathrm{C}$ for 5 min and then placed on ice for $30 \mathrm{~min}$. The labeled $\lambda$-DNA at $0.005 \mu \mathrm{g} / \mu \mathrm{L}$ was mixed with unlabeled $\lambda$-DNA at $0.83 \mu \mathrm{g} / \mu \mathrm{L}$ to reach a final entanglement concentration of $0.36 \mu \mathrm{g} / \mu \mathrm{L}$. Propyl gallate $(4 \%)$ was added to the sample as an oxygen scavenger. The sample was then flowed into a channel sandwiched between a cover glass and a microscope slide, sealed by nail polish and left to incubate for $10 \mathrm{~min}$. The fluorescence from the sample slide was collected by a water immersion objective (Olympus $60 \times$, $\mathrm{NA}=1.2$ ) and focused onto a CCD camera (Roper, Cascade 512B). We first measured the diffusion coefficient of $\lambda$-DNA immobilized on a glass substrate (Table 1). The reading of $0.00095 \pm 0.00033$ indicates excellent instrumentation stability. We also measured the diffusion coefficient of healthy labeled $\lambda$-DNA in free solution (no entanglement), which yielded a value of $0.404 \pm 0.054 \mu \mathrm{m}^{2} / \mathrm{s}$, in good agreement with the literature [16]. In terms of single-molecule data selection, large fluorescent spots were not analyzed to exclude clumps of strands or multiple intra-strand crosslinks. The fluorescent signals were monitored for 60 frames with a $0.2 \mathrm{~s}$ exposure time for each frame. The diffusion coefficients were calculated from the mean-square-displacements of the fluorescent molecules using MatLab programs [17].

\subsection{Gel Electrophoresis}

Preparation of the agarose gel consisted of $10 \mathrm{~mL}$ of $10 \times$ TAE buffer, $90 \mathrm{~mL}$ of Milli-Q water, $17 \mu \mathrm{L}$ of ethidium bromide (at $5 \mathrm{mg} / \mathrm{mL}$ ), and $1.0 \mathrm{~g}$ of agarose for a $1.0 \%$ concentration. Each lane was loaded with $5 \mu \mathrm{L}$ of $1 \times$ TAE, $7 \mu \mathrm{L}$ of loading buffer, and $20 \mu \mathrm{l}$ of varying irradiated $\lambda$-DNA (at $0.05 \mu \mathrm{g} / \mu \mathrm{L}$ ). From left to right (Fig. 1), the lanes contained healthy $\lambda$-DNA, $6 \mathrm{~min}, 12 \mathrm{~min}, 20 \mathrm{~min}$, and 40 min exposed $\lambda$-DNA. $1 \times$ TAE was used for the running buffer and let run for about $1 \mathrm{hr}$ at 7 milliamps.

\subsection{TEM Imaging}

Sample preparation for TEM entails separate hypophase and hyperphase solutions. The hypophase contained $0.01 \mathrm{M}$ of Tris buffer, $0.001 \mathrm{M}$ of EDTA, 40\% of formamide, Milli-Q water, and functioned as a supporting medium for the hyperphase. The hyperphase ( $50 \mu \mathrm{L}$ total volume) contained $50 \mu \mathrm{g} / \mu \mathrm{L}$ of cytochrome c attaches to $0.05 \mu \mathrm{g} / \mu \mathrm{L}$ of dsDNA, $0.1 \mathrm{M}$ Tris buffer, $0.01 \mathrm{M}$ EDTA, and $40 \%$ of formamide (at 98\%). The hyperphase moved down the slide, stretching out the $\lambda$-DNA strands. When the $\lambda$-DNA reached the hyperphase/hypophase interface, the $\lambda$-DNA diffused on top of the hypophase. A grid skimmed over the interface, collecting the $\lambda$-DNA labeled with cytochrome $\mathrm{c}$ on the surface. Then the grid was placed on a droplet of uranyl acetate, which stained the cytochrome c. Images were recorded at magnification ranging from $15,000 \times$ to $400,000 \times$ with a Hitachi 7600 transmission electron microscope at $120 \mathrm{kV}$.

\section{Acknowledgements}

The authors thank Dr. Lyndon Larcom for insightful discussions. The authors acknowledge an ACS-PRF grant \#45214-G7, an NSF grant CBET-0736037 and an NSF Career award to Ke. 


\section{References and Notes}

1. Mitchell, D.; Karentz, D. Environmental UV Photobiology; Plenum Press: New York, NY, 1993.

2. Sinha, R.; Hader, D. UV-induced DNA damage and repair: a review. Photochem. Photobiol. Sci. 2002, 1, 225-236.

3. Tommasi, S.; Denissenko, M.; Pfeifer, M. Sunlight induces pyrimidine dimers preferentially at 5methylcytosine bases. Cancer Res. 1997, 57, 4727-4730.

4. Yoon, J.; Lee, C.; O’Connor, T.; Yasui, A.; Pfeifer, G. The DNA damage spectrum produced by simulated sunlight. J. Mol. Biol. 2000, 299, 681-693.

5. Pfeifer, G.; Drouin, R.; Riggs, A.; Holmquist, G.; Binding of transcription factors creates hot spots for UV photoproducts in vivo. Molecular and Cellular Biology 1992, 12, 1798-1804.

6. Friedberg, E. DNA repair; W. H. Freeman \& Co.: New York, NY, 1985.

7. de Gennes, P. Reptation of a polymer chain in the presence of fixed obstacles. J. Chem. Phys. 1971, 55, 572-579.

8. de Gennes, P. Scaling Concepts in Polymer Physics; Cornell University Press: New York, NY, 1979.

9. Doi, M.; Edwards, S.F. The Theory of Polymer Dynamics; Oxford Science Publications: New York, NY, 1986.

10. Park, H.; Zhang, K.; Ren, Y.; Nadji, S.; Sinha, N.; Taylor, J.; Kang, C. Crystal structure of a DNA decamer containing a cis-syn thymine dimer. Proc. Natl. Acad. Sci. U.S.A. 2002, 99, 15965-15970.

11. Schallhorn, K.; Freedman, K.; Moore, J.; Lin, J.; Ke, P.C. Single-molecule DNA flexibility in the presence of base-pair mismatch. Appl. Phys. Lett. 2005, 87, 033901-1-3.

12. Nejedly, K.; Kittner, R.; Pospsilova, S.; Kypr, J. Crosslinking of the complementary strands of DNA by UV light: dependence on the oligonucleotide composition of the UV irradiated DNA. Biochimica et Biophysica Acta 2001, 1517, 365-375.

13. Bourre, F.; Renault, G.; Sarasin, A. Sequence effect on alkali-sensitive sites in UV-irradiated SV40 DNA. Nucleic Acids Res. 1987, 15, 8861-8875.

14. Cloutier, T.E.; Widom, J. Spontaneous sharp bending of double-stranded DNA. Mol. Cell 2004, 14, 355-362.

15. Yan, J.; Marko, J.F. Localized single-stranded bubble mechanism for cyclization of short bouble helix DNA. Phys. Rev. Lett. 2004, 93, 108108-1-4.

16. Smith, D.E.; Perkins, T.T.; Chu, S. Self-Diffusion of an Entangled DNA Molecule by Reptation. Phys. Rev. Lett. 1995, 75, 4146-4149.

17. Freedman, K.O.; Lee J.; Li, Y.; Luo, D.; Skobeleva, V.B.; Ke, P.C. Diffusion of single starbranched dendrimer-like DNA. J. Phys. Chem. B 2005, 109, 9839-9842.

(C) 2008 by MDPI (http://www.mdpi.org). Reproduction is permitted for noncommercial purposes. 